\title{
CCR2 and coronary artery disease: a woscops substudy
}

\author{
David J Dow*1, Alex D McMahon², lan C Gray ${ }^{1,4}$, Chris J Packard³ and Pieter HE Groot ${ }^{1}$
}

\begin{abstract}
Background: Several lines of evidence support a role for CCL2 (monocyte chemotactic protein-1) and its receptor CCR2 in the development of atherosclerosis. The aim of the present study was to determine the association of the CCR2 Val64lle polymorphism with the development of coronary artery disease in the WOSCOPS study sample set.

Findings: A total of 443 cases and 1003 controls from the West of Scotland Coronary Prevention Study (WOSCOPS) were genotyped for the Val64lle polymorphism in the CCR2 gene. Genotype frequencies were compared between cases and controls. The CCR2 Val64lle polymorphism was found not to be associated with coronary events in this study population (odds ratio $1.15,95 \% \mathrm{Cl} 0.82-1.61, \mathrm{p}=0.41$ ).

Conclusions: This case-control study does not support an association of the CCR2 Val64lle polymorphism with coronary artery disease in the WOSCOPS sample set and does not confirm a possible protective role for CCR2 Val64lle in the development of coronary artery disease.
\end{abstract}

\section{Introduction}

There is increasing evidence from numerous studies to indicate that the over-recruitment of leukocytes, especially monocytes, is central to the pathology of atherosclerosis [1-4]. Consequently, atherosclerosis is considered now to be an inflammatory disease. Chemokines are inflammatory chemotactic cytokines that play a role in leucocyte recruitment and the chemokine CCL2 (monocyte chemoattractant protein-1 or MCP-1) has been found to be highly expressed in human atherosclerotic plaques [5]. CCL2 attracts monocytes as well as $\mathrm{T}$ lymphocytes and mediates its effects by binding to $\mathrm{G}$ protein coupled receptors expressed on the surface of target cells [6]. The most prominent receptor for CCL2 is CCR2 [7] and its binding to this receptor has been shown to result in recruitment of monocytes into the subendothelial space [8]. Further evidence for the role of CCL2 and its receptor CCR2 in the pathology of atherosclerosis has come from gene knock-out experiments in mice. CCR2 (/-) mice show defects in leukocyte adhesion and monocyte/macrophage recruitment [9]. The absence of CCR2 on macrophages protects those mice from developing

\footnotetext{
* Correspondence: David.J.Dow@gsk.com

1 GlaxoSmithKline Medicines Research Centre, Gunnels Wood Road, Stevenage, SG1 2NY, UK
}

atherosclerosis [10-12]. Moreover, mice lacking the ligand CCL2 (-/-) also showed decreased lesion size and a significant reduction of macrophages in lesions [13]. In addition, overexpression of CCL2 results in an increase in macrophage number within the lesions [14]. Taken together, these studies strongly suggest a direct role for CCL2 and CCR2 in monocyte recruitment and in the pathology of atherosclerosis. The CCR2 gene comprises two exons and is subject to alternative splicing [6]. A G to A coding polymorphism in exon 2 of the gene has been reported which results in a Val to Ile substitution at position 64. Evidence for this polymorphism having an effect on the function of CCR2 comes from studies of HIV infected individuals. CCR2 and CCR5 are required for the entry of the virus into lymphocytes. Those individuals carrying the CCR2 Ile allele were found to progress to AIDS 2-4 years later than individuals homozygous for the common Val allele [15]. We and others have reported on the role of this polymorphism in the development of coronary artery disease, but the findings do not all appear to be in agreement. In our previous study [16] we looked at the effect of the Val64Ile polymorphism in a cohort of first degree relatives of patients with premature coronary artery disease. The extent of coronary artery calcification was found to be significantly lower in subjects with the CCR2 Ile64 variant than in subjects carrying two Val64 
alleles which we interpreted as being beneficial. A similar conclusion was drawn by Szalai et. al. [17] based on the absence of any CCR2 Ile64 homozygotes in the cases group of a CAD case-control study. In contrast, Ortlepp et. al. [18] found the Ile64 allele to be associated with an increased risk for MI (myocardial infarction) and heart failure in subjects of age $<65 \mathrm{y}$ in a large cohort of patients who underwent left ventricular catheterization and also Gonzalez et. al. [19] were unable to find a protective effect of the Ile64 allele MI in a case control study. To investigate further our previous suggestion for a protective effect of Ile64 in coronary atherosclerosis, we examined the role of the Val64Ile polymorphism in a nested case-control sample from the West of Scotland Coronary Prevention (WOSCOPS) study.

\section{Methods}

\section{Woscops}

The West of Scotland Coronary prevention study (WOSCOPS) was a randomised, double-blind, placebo controlled trial of pravastatin [20]. The aim of the study was to examine the effect of pravastatin in preventing non fatal MI or death from coronary artery disease. A total of 6595 men aged 45-64 years (mean 55.2 years) with raised cholesterol levels were randomised in equal numbers to pravastatin after initial screening of approximately 81,000 subjects. Individuals had no history of myocardial infarction and had normal renal and hepatic function. Cases were defined as those individuals who, during the course of the five year study, died from definite coronary artery disease (CAD) or who experienced nonfatal acute myocardial infarction, or who were subject to re-vascularisation. Controls, also taken from the original cohort of 6595 men with raised cholesterol levels, did not have a cardiac event. Each case was matched with 2 con- trols on the basis of age and smoking status. In this present study 443 cases and 1003 controls were examined where specimens had been stored for genetic analysis. 182 of the cases $(41 \%)$ and 509 controls (51\%) received pravastatin treatment. Ethical approval for the study was received from each of the four ethical committees in the west of Scotland (Lanarkshire, Glasgow, Argyle \& Clyde and Dumfries \& Galloway). Informed consent for the present genetics study was received from all individuals.

\section{Val64lle Genotyping}

The samples in this study were genotyped using the amplifluor genotyping method [21]. Using this method, two allele specific primers are designed, each of which is complementary to either the wild type or variant allele of the polymorphism at the 3' most base of the primer. Each primer has a $5^{\prime}$ tail which enables it to bind to one of two "uniprimers". A "common" primer is the reverse primer for the PCR reaction. Each uniprimer is labelled with a fluorescent dye (JOE or FAM, Applied Biosystems). During the course of the reaction, uniprimers fluoresce if the SNP (Single Nucleotide Polymorphism) allele is complementary to the end base of the primer. The Val64Ile polymorphism is a $\mathrm{G}$ to A polymorphism situated in exon 2 of the $\mathrm{b}$ isoform of CCR2. The presence of a high fluorescence signal for FAM indicates a G/G genotype, a high level of JOE fluorescence indicates an A/A genotype. Intermediate levels of FAM and JOE fluorescence indicate a heterozygous G/A genotype. The fluorescence measurements were carried out using an ABI 7700 sequence detection system (Applied Biosystems).

The primer sequences used were as follows:

Allele 1 G GAAGGTGACCAAGTTCATGCTTTTGCAGTTTATTAAGATGAGGAC

Table 1: CCR2 Val64lle genotypes and allele frequencies for cases and controls.

\begin{tabular}{|c|c|c|c|c|c|}
\hline $\begin{array}{l}\text { Phenotype and } \\
\text { Genotype }\end{array}$ & $\begin{array}{l}\text { Cases }(n=443) \\
\text { (frequency \%) }\end{array}$ & $\begin{array}{l}\text { Controls } \\
(n=1003) \\
\text { (frequency \%) }\end{array}$ & $\begin{array}{l}\text { Odds Ratio } \\
\text { (Ile/Ile or Val/Ile) }\end{array}$ & $\begin{array}{l}95 \% \text { confidence } \\
\text { interval }\end{array}$ & P-value \\
\hline \multicolumn{6}{|l|}{$\begin{array}{l}\text { Death/Non-fatal } \\
\text { event }\end{array}$} \\
\hline $\mathrm{Val} / \mathrm{Val}$ & $384(86.7)$ & $884(88.1)$ & & & \\
\hline $\begin{array}{l}\text { Val/lle or Ile/lle } \\
\text { (pooled) }\end{array}$ & 59 (13.3) & 119 (11.9) & 1.15 & $0.82-1.61$ & 0.410 \\
\hline Val & 0.93 & 0.94 & & & \\
\hline Ile & 0.07 & 0.06 & & & \\
\hline
\end{tabular}


Allele 2 A GAAGGTCGGAGTCAACGGATTTTTGCAGTTTATTAAGATGAGGAT

Common 1 GCTCTACTCGCTGGTGTTCAT

The PCR product size was $74 \mathrm{bp}$.

\section{Statistical analysis}

The WOSCOPS Biobank is a generic tool designed for various case-control studies. The power of the design depends on the gene frequency of the genotype being studied. A case-control study with 443 cases and 1003 controls can detect with $80 \%$ power a rate-ratio of 1.71 for a gene frequency of $5 \%$, a rate-ratio of 1.50 for a gene frequency of $10 \%$, and a rate-ratio of 1.42 for a gene frequency of $15 \%$. A chi-squared analysis was used to determine if the distribution of genotypes was in HardyWeinberg equilibrium. Conditional logistic regression was used to assess the effect of individual alleles by calculating odds ratios with associated 95\% confidence interval.

\section{Results \\ Study subjects}

The CCR2 Val64Ile genotype was determined in a total of 443 cases and 1003 control individuals from the WOSCOPS sample set. The CCR2 polymorphism was found to be in Hardy-Weinberg equilibrium (Cases: chisquared $=2.25, \mathrm{p}=0.13$; Controls: chi-squared $=0.02, \mathrm{p}=$ $0.9)$. Genotype frequencies were as follows: Val/Val 1268 (87.7\%), Val/Ile $174(12 \%)$ and Ile/Ile $4(0.3 \%)$. This gave a minor allele frequency for the Ile allele of 0.06. Due to the small number of Ile/lle homozygotes, we pooled heterozygotes and homozygotes for the minor allele prior to analysis. Table 1 shows the results of statistical analysis. For the clinical endpoint of death from definite coronary artery disease (CAD), non-fatal acute myocardial infarction, or a re-vascularisation event, the odds ratio for the Ile allele was 1.15 (95\% CI 0.82 - 1.61).

In addition, the analysis of the re-vascularisation end point only produced an odds ratio of 0.78 (95\% CI 0.33 1.87), the odds ratio for the non-fatal acute myocardial infarction endpoint was 1.28 (95\% CI 0.89 - 1.86) and for the death from definite coronary artery disease (CAD) endpoint it was 0.96 (95\% CI 0.45 - 2.08). All three subgroup analyses were non-significant.

\section{Discussion}

For a complex pathology such as coronary artery disease, there are likely to be many susceptibility genes which play a role in determining the phenotype [22]. Based upon previous work implicating the CCR2 gene in the progression of atherosclerosis, we sought to further assess the role of the Val64Ile polymorphism in the clinical endpoint of coronary artery disease. In this study we examined the genotypes of 443 cases and 1003 control individuals from the WOSCOPS study. The results obtained for both the combined and single endpoint analyses did not indicate a significant difference in genotype frequencies between cases and controls and so do not suggest a significant role for this polymorphism in the development of coronary artery disease. A number of recent studies have looked at the association of the CCR2 Val64Ile polymorphism and clinical endpoints associated with atherosclerosis. In our previous study the extent of coronary artery calcification was significantly lower in subjects with the CCR2 Ile64 variant than in subjects carrying two Val64 alleles [16] suggesting a beneficial effect for the Ile64 allele. Coronary artery calcification has previously been shown to be correlated with the extent of coronary atherosclerotic lesions [23]. The results of our present study are not in agreement with our previous study and there are several potential explanations for this. Firstly the definition of cases was different. Valdes et al. defined cases as male or female first degree relatives of subjects with premature coronary artery disease and there were various exclusion criteria including smoking status. Subjects were non-Hispanic whites from the Pennsylvania area. In the Woscops study, all subjects were men from the west of Scotland with pre-determined cut off values for cholesterol and LDL/cholesterol and smokers were included. The phenotypes are also different between the studies. Valdes et al. measured coronary artery calcification (CAC) using tomography. In Woscops the endpoints were death from coronary artery disease (CAD), non-fatal acute myocardial infarction, or re-vascularisation. In addition the sample sets were different with 400 cases and 1003 controls for this study and 662 subjects in the CAC study. In Valdes et al, the genotype frequencies were compared between individuals in a high or low CAC value group whereas the cases in Woscops were those with the aforementioned endpoints. Also in Woscops, each case was matched to 2 controls. It is possible that these differences in study design or geographical location of subjects could account for the different conclusions from the two studies examining the same Val64 Ile polymorphism. Other evidence attributing a role for CCR2 in the development of atherosclerosis has been shown [18]. In contrast, here the Ile allele was found to be positively associated with myocardial infarction and heart failure in patients less than 65 years of age. There was no association of the CCR2 genotype with atherosclerosis, but the CCR2 Ile allele appeared to predispose patients to myocardial infarction before 65 years of age. In other work, the role of CCR2 Val64lle was not supported in studies of both myocardial infarction and coronary artery disease as diagnosed by angiography in patients versus controls $[19,24]$. Also recently Bjarnadottir et al. [25] were unable to find any effect of the CCR2 Val64Ile mutation in a large Icelandic retrospective 
nested case-control study of MI survivors. Again it cannot be excluded that the different conclusions of these studies could be related to differences in study design, clinical endpoints of the coronary artery disease phenotype or that subjects were derived from different geographical populations where there are differences in genetic or environmental factors [26]. The WOSCOPS sample set is a large, well characterised cohort comprising individuals from the same geographical location. In summary, the results of this present study do not support a role for the CCR2Val64Ile polymorphism in the endpoints of death from coronary artery disease (CAD), nonfatal acute myocardial infarction, or re-vascularisation.

\section{Conclusions}

This CCR2 association study does not confirm a role for the CCR2 Val64Ile polymorphism in the development of coronary artery disease.

\section{Competing interests}

DJD is an employee of GlaxoSmithKline. ICG and PHEG are former employees of GlaxoSmithKline.

\section{Authors' contributions}

DJD - Designed, planned and managed the CCR2 study, designed genotyping assays and wrote the manuscript. ADM - Designed the CCR2 study, preformed statistical analysis of the genotyping data and edited the manuscript. ICG Designed the CCR2 study and edited the manuscript. CJP - Advised on the study, is a main investigator of the WOSCOPS study and edited the manuscript. PHEG - managed the study and edited the manuscript. All authors read and approved the final manuscript.

\section{Acknowledgements}

The polymorphism work described was funded by GlaxoSmithKline.

\section{Author Details}

'GlaxoSmithKline Medicines Research Centre, Gunnels Wood Road, Stevenage, SG1 2NY, UK

${ }^{2}$ Robertson Centre for Biostatistics, Boyd Orr Building, University of Glasgow, G12 8QQ, UK,

${ }^{3}$ Division of Medical Sciences, University of Glasgow, Western Infirmary, Glasgow, G11 6NT, UK and

${ }^{4}$ Current Address: Takeda Singapore, 10 Biopolis Road, 03-01/02 Chromas, 138670, Singapore

Received: 14 September 2009 Accepted: 2 February 2010 Published: 2 February 2010

\section{References}

1. Ross R: Atherosclerosis--an inflammatory disease. NEngl J Med 1999, 340:115-126.

2. Bursill CA, Channon KM, Greaves DR: The role of chemokines in atherosclerosis: recent evidence from experimental models and population genetics. Curr Opin Lipido/ 2004, 15:145-149.

3. Gautier EL, Jakubzick C, Randolph GJ: Regulation of the migration and survival of monocyte subsets by chemokine receptors and its relevance to atherosclerosis. Arterioscler Thromb Vasc Bio/ 2009 29:1412-1418

4. Tacke F, Alvarez D, Kaplan TJ, Jakubzick C, Spanbroek R, Llodra J, et al: Monocyte subsets differentially employ CCR2, CCR5, and CX3CR1 to accumulate within atherosclerotic plaques. J Clin Invest 2007, 117:185-194.

5. Nelken NA, Coughlin SR, Gordon D, Wilcox JN: Monocyte chemoattractant protein-1 in human atheromatous plaques. J Clin Invest 1991, 88:1121-1127.
6. Horuk R: Molecular properties of the chemokine receptor family. Trends Pharmacol Sci 1994, 15:159-165.

7. Charo IF, Myers SJ, Herman A, Franci C, Connolly AJ, Coughlin SR: Molecular cloning and functional expression of two monocyte chemoattractant protein 1 receptors reveals alternative splicing of the carboxyl-terminal tails. Proc Natl Acad Sci USA 1994, 91:2752-2756.

8. Weber C: Novel mechanistic concepts for the control of leukocyte transmigration: specialization of integrins, chemokines, and junctional molecules. J Mol Med 2003, 81:4-19.

9. Kuziel WA, Morgan SJ, Dawson TC, Griffin S, Smithies O, Ley K, et al. Severe reduction in leukocyte adhesion and monocyte extravasation in mice deficient in CC chemokine receptor 2. Proc Natl Acad Sci USA 1997, 94:12053-12058.

10. Boring L, Gosling J, Chensue SW, Kunkel SL, Farese RV Jr, Broxmeyer HE, et al: Impaired monocyte migration and reduced type 1 (Th1) cytokine responses in C-C chemokine receptor 2 knockout mice. J Clin Invest 1997, 100:2552-2561.

11. Dawson TC, Kuziel WA, Osahar TA, Maeda N: Absence of CC chemokine receptor-2 reduces atherosclerosis in apolipoprotein E-deficient mice. Atherosclerosis 1999, 143:205-211.

12. Guo J, Van Eck M, Twisk J, Maeda N, Benson GM, Groot PH, et al:: Transplantation of monocyte CC-chemokine receptor 2-deficient bone marrow into ApoE3-Leiden mice inhibits atherogenesis. Arterioscler Thromb Vasc Biol 2003, 23:447-453.

13. Gu L, Okada Y, Clinton SK, Gerard C, Sukhova GK, Libby P, et al:: Absence of monocyte chemoattractant protein-1 reduces atherosclerosis in low density lipoprotein receptor-deficient mice. Mol Cell 1998, 2:275-281.

14. Aiello RJ, Bourassa PA, Lindsey S, Weng W, Natoli E, Rollins BJ, et al. Monocyte chemoattractant protein-1 accelerates atherosclerosis in apolipoprotein E-deficient mice. Arterioscler Thromb Vasc Biol 1999, 19:1518-1525

15. Smith MW, Dean M, Carrington M, Winkler C, Huttley GA, Lomb DA, et al: Contrasting genetic influence of CCR2 and CCR5 variants on HIV-1 infection and disease progression. Hemophilia Growth and Development Study (HGDS), Multicenter AIDS Cohort Study (MACS), Multicenter Hemophilia Cohort Study (MHCS), San Francisco City Cohort (SFCC), ALIVE Study. Science 1997, 277:959-965.

16. Valdes AM, Wolfe ML, O'Brien EJ, Spurr NK, Gefter W, Rut A, et al: Val64lle polymorphism in the $\mathrm{C}-\mathrm{C}$ chemokine receptor 2 is associated with reduced coronary artery calcification. Arterioscler Thromb Vasc Biol 2002, 22:1924-1928

17. Szalai C, Duba J, Prohaszka Z, Kalina A, Szabo T, Nagy B, et al.: Involvement of polymorphisms in the chemokine system in the susceptibility for coronary artery disease (CAD). Coincidence of elevated $L p(a)$ and MCP-1 -2518 G/G genotype in CAD patients. Atherosclerosis 2001, 158:233-239.

18. Ortlepp JR, Vesper K, Mevissen V, Schmitz F, Janssens U, Franke A, et al: Chemokine receptor (CCR2) genotype is associated with myocardial infarction and heart failure in patients under 65 years of age. $\mathrm{J}$ Mol Med 2003, 81:363-367.

19. Gonzalez P, Alvarez R, Batalla A, Reguero JR, Alvarez V, Astudillo A, et al: Genetic variation at the chemokine receptors CCR5/CCR2 in myocardial infarction. Genes Immun 2001, 2:191-195.

20. Screening experience and baseline characteristics in the West of Scotland Coronary Prevention Study. The WOSCOPS Study Group. West of Scotland Coronary Prevention Study. Am J Cardiol 1995, 76:485-491.

21. Khripin Y: High-throughput genotyping with energy transfer-labeled primers. Methods Mol Biol 2006, 335:215-240.

22. Lusis AJ: Genetic factors in cardiovascular disease. 10 questions. Trends Cardiovasc Med 2003, 13:309-316.

23. Rumberger JA, Simons DB, Fitzpatrick LA, Sheedy PF, Schwartz RS: Coronary artery calcium area by electron-beam computed tomography and coronary atherosclerotic plaque area. A histopathologic correlative study. Circulation 1995, 92:2157-2162.

24. Apostolakis S, Baritaki S, Kochiadakis GE, Igoumenidis NE, Panutsopulos D, Spandidos DA: Effects of polymorphisms in chemokine ligands and receptors on susceptibility to coronary artery disease. Thromb Res 2007, 119:63-71

25. Bjarnadottir K, Eiriksdottir G, Aspelund T, Gudnason V: Examination of genetic effects of polymorphisms in the MCP-1 and CCR2 genes on Ml in the Icelandic population. Atherosclerosis 2006, 188:341-346. 
26. Kathiresan S, Newton-Cheh C, Gerszten RE: On the interpretation of genetic association studies. Eur Heart J 2004, 25:1378-1381.

\section{doi: 10.1186/1756-0500-3-31}

Cite this article as: Dow et al., CCR2 and coronary artery disease: a woscops substudy BMC Research Notes 2010, 3:31

Submit your next manuscript to BioMed Central and take full advantage of:

- Convenient online submission

- Thorough peer review

- No space constraints or color figure charges

- Immediate publication on acceptance

- Inclusion in PubMed, CAS, Scopus and Google Scholar

- Research which is freely available for redistribution

Submit your manuscript at www.biomedcentral.com/submit 